\title{
Desafios da prática docente: diálogos com a Educação Social
}

\author{
Challenges of teaching practice: \\ dialogues with Social Education
}

Fábio Santos de ANDRADE ${ }^{1}$

\begin{abstract}
Resumo
Pretende-se afirmar a necessidade urgente de mudanças no sistema educacional brasileiro. Mudanças que devem ocorrer no âmbito dos governos, das escolas, das comunidades e das famílias, para, assim, dotar a escola de autonomia e torná-la participativa e democrática. Assim, esse texto, partindo da reflexão sobre a escola atual e sua função formadora de seres humanos reflexivos, críticos e politicamente engajados, traz a Educação Social como aporte teórico-metodológico para a formação de educadores comprometidos com a vida, com o respeito às diversidades, com a educação humanizada e com a luta pela justiça social.
\end{abstract}

Palavras-chave: Educação. Formação de professores. Educaçáo Social. Justiça Social.

\begin{abstract}
We intend to affirm the urgent need for changes in the Brazilian educational system. Changes that must occur within governments, schools, communities and families, in order to endow the school with autonomy and make it participatory and democratic. Thus, this text, starting from the reflection on the current school and its role as a reflexive, critical and politically engaged human being, brings Social Education as a theoretical and methodological contribution for the formation of educators committed to life, with respect for diversity, with humanized education and with the struggle for social justice.
\end{abstract}

Keywords: Education. Teacher training. Social Education. Social justice.

1 Educador Social. Professor Adjunto do Departamento Acadêmico de Ciências da Educação (DACIE) e do Programa de Pós-Graduação em Educação Escolar (PPGEE), da Universidade Federal de Rondônia (UNIR). Graduado em História e Especialista em Políticas Públicas e Educaçáo pela Universidade Estadual do Sudoeste da Bahia (UESB). Mestre em Ciências Sociais (área de Sociologia) pela Pontifícia Universidade Católica de São Paulo (PUC). Doutor em Educação pela Universidade Federal de Mato Grosso (UFMT). Pesquisador da área da História Social e Sociologia da Juventude. Líder do Grupo de Estudos Pedagógicos (GEP). Coordenador do grupo de estudos sobre crianças e adolescentes em situaçấo de risco (DACIE/UNIR). E-mail: fasaan@hotmail.com / fabioandrade@unir.br

R. Educ. Públ.

\section{Cuiabá}

v. 28

n. 68 p. $393-401$ maio/ago. 2019 


\section{Reflexões iniciais sobre a escola e sua função social}

Em um Estado Democrático de Direitos, a educação se torna uma estratégia de avanço político e de conquista da tão destacada cidadania. Nessa perspectiva, o discurso sobre cidadania intensificou-se pelo Brasil durante a década de 1990, e fez com que se tornassem evidentes os discursos que ressaltam a necessidade de uma educação para a cidadania, da conquista da cidadania, do exercício da cidadania, referindo-se à necessidade de determinados grupos sociais assimilarem códigos, símbolos e signos para a vida social suleada pelo Estado. Logo, no contexto atual, tornou-se muito difícil definir o que é cidadania ou como exercê-la.

De acordo com Oliveira (1999, não paginado), o caminho não é definir cidadania como ausência ou carência, mas sim como plenitude. Para ele, a cidadania seria:

[...] uma espécie de estado de espírito em que o cidadão fosse alguém dentro da sociedade - evidentemente não haveria cidadáo fora dela -, fosse alguém que estivesse em pleno gozo de sua autonomia, e esse gozo de sua autonomia não fosse um gozo passivo, mas sim um gozo ativo, de plena capacidade de intervir nos negócios da sociedade, e através de outras mediaçóes, intervir também nos negócios do Estado que regula a sociedade da qual ele faz parte. Isso na concepção ativa de cidadania, não apenas de quem recebe, mas na verdade de ator que usa recursos econômicos, sociais, políticos e culturais para atuar no espaço público.

Tendo como base essa definição, é possível afirmar que a condição de cidadania é estabelecida por meio de regras institucionalizadas. São os direitos traduzidos em códigos, símbolos e signos da sociedade que condicionam o padrão de cidadão, que, por sua vez, dialoga cotidianamente com esses códigos, símbolos e signos, alterando-os sempre que necessário. Todavia, quando as instituiçóes passam a ser politicamente controladas pela minoria, o modelo de cidadão é imposto e a maioria é condicionada a obedecer-lhe, desconstruindo princípios básicos de acesso aos direitos à justiça social.

Atualmente, evidencia-se um período em que se acentua o desmanche dos direitos, em que boa parte da população de baixa renda é lançada num mundo onde a discriminação e as exclusões sociais se processam. Dessa forma, torna-se impossível falar em direitos sociais, pois:

Falar em direitos sociais seria falar de sua impotência em alterar a ordem do mundo, impotência que se arma no descompasso entre a grandiosidade dos 
ideais e a realidade bruta das discriminaçóes, exclusóes e violências que atingem maiorias. Além disso, e talvez o mais importante, náo poderíamos ir muito além do que constatar - e lamentar - os efeitos devastadores das mudanças em curso no mundo contemporâneo, demolindo direitos que mal ou bem garantem prerrogativas que compensam a assimetria de posiçóes nas relaçóes de trabalho e poder, e fornecem proteçóes contra as incertezas da economia e os azares da vida. (TELLES, 2006, p. 174).

Segundo Oliveira (1999), a população, principalmente as pessoas oriundas das classes populares e de baixa renda, vive um período em que há tentativas efetivas de desconstruçáo da cidadania, e essas tentativas emergem do Estado, do setor privado ou dos movimentos sociais. Assim sendo, cidadão passa a ser aquele que consegue adaptar-se e obedecer às regras sociais estabelecidas pelo Estado, não o que participa da sua formulação. Os que não lhes obedecem tornam-se marginais que buscam a justiça social por meios que, muitas vezes, desembocam na violência. É nesse contexto de complexidades que a escola se apresenta como espaço de disseminação dos códigos, símbolos e signos, considerados fundamentais para a vida social e capazes de reduzir as desigualdades.

A escola pública que temos hoje é um modelo imposto pelo Estado e que deve atender as suas necessidades básicas. Ele não está preocupado em despertar o senso crítico do aluno, mas sim lhe dar um certificado de conclusão. Quando grande parte dos governantes pensa em escola pública, eles têm "como medidas centrais à redução das taxas de repetência e evasão ou a permanência no sistema escolar." (ARROYO, 1991, p.17). Não é interessante para eles que alunos de escolas públicas se tornem pensadores críticos ou que ascendam socialmente, é interessante que continuem na classe em que estão e que se tornem a mão de obra barata para o país.

Apesar de tantas mudanças ocorridas na legislação educacional brasileira após 1996, e que teoricamente garantem uma educação gratuita e de qualidade para todos, muitos ainda estão fora da escola. A escola que temos se tornou viável, porém, muitas vezes inviável, devido as suas burocracias educacionais. Sendo assim, consideramos importante refletir sobre o modelo de escola que temos e que tentamos subordinar nossas crianças e adolescentes e sobre como nossos professores e professoras têm sido preparados(as) para lidar com as diversidades, que não podem mais ser ignoradas no cotidiano da escola.

Culturalmente, delegamos, de forma exclusiva, à escola a função de capacitar e certificar seres educados e devemos considerar que essa função vem sendo desempenhada, em muitas escolas, de forma absurda e equivocada quando tomamos como base o verdadeiro sentido do ato de educar. Vemos que o sistema educacional brasileiro se encontra defasado em decorrência de várias 
crises enfrentadas pelo ensino, tais como as ligadas ao despreparo do professor diante das novas demandas do cotidiano escolar e a sua má remuneraçáo, que acarreta acúmulo de carga horária e, tantas vezes, desânimo, cansaço e doenças diversas. Além disso, há falta de recursos didáticos e financeiros disponíveis para a realização do trabalho.

Sabemos que a escola atual supervaloriza um ensino fragmentado, com índice de rendimento qualitativo baixíssimo, objetivando diminuir a repetência, a evasão e o analfabetismo, excluindo aqueles que não se adaptam, sob alegação de que correspondem ao percentual referente à evasão. Muitos alunos que conseguem suportar a escola se tornam alunos apáticos com relaçáo à leitura, à pesquisa e principalmente à valorização de sua cultura. Com isso, surge a pergunta: Qual é a essência de uma escola de qualidade? A escola deve ser encarada "como um espaço de produção e disseminação da cultura, de conhecimentos e principalmente de luta contra a desigualdade." (MILET, 1999, p. 17).

Concebendo a educação como uma responsabilidade de todos: professores, pais, alunos e comunidade. Incentivando a mobilização da população em defesa do ensino público de qualidade, se torna possível pressionar ainda mais o Estado para que cumpra o seu dever de garantir a educação pública, gratuita e de qualidade para toda a população.

\section{A escola em diálogo com a Educação Social}

Ainda visualizamos a educação como caminho transformador, no entanto, transformar a escola em um ambiente de formaçáo de seres críticos, reflexivos e socialmente conscientes não é tarefa fácil. Tal mudança parte da vontade política de governantes, sociedade, familiares, equipe pedagógica das escolas e principalmente da relação professor/aluno, ou melhor, educador/educando.

Culturalmente, delegamos à escola a função de capacitar e certificar seres educados, considerando-a como ensino formal e caracterizando as outras práticas educativas como não formais. Ao valorizar as ações educativas que rompem as paredes da escola e que têm possibilitado uma educação social humanizada, desconsidero os termos formal e não formal e utilizo educação escolar e não escolar, considerando o valor e o cuidado metodológico exigido em ambas.

Romper com os paradigmas da dominação, existentes no contexto políticosocial e que têm conduzido a educaçáo brasileira no decorrer dos anos, se faz urgente e, na perspectiva de provocar a existência de uma escola pronta para lidar e respeitar as diversidades, faz-se necessário elaborar e colocar em prática planos de ação que consigam superar, a médio e longo prazo, os valores 
e atitudes ultrapassados e que estão cristalizadas nas práticas educacionais do Brasil. Cada escola deve ser capaz de lidar com as diversidades, respeitando as singularidades de cada indivíduo, possibilitando que todos os envolvidos se sintam representados em sua prática e exerçam seu poder, dialogando e participando das tomadas de decisão.

Para que se torne possível tal transformação é necessário que o educador seja comprometido com uma educaçáo emancipadora e capaz de transformar positivamente a vida de seus educandos. É necessário que o educador seja referência positiva de adulto, capaz de provocar mudanças históricas e sociais na vida de seus educandos.

A educação é uma ação de imenso poder na formação de seres críticos, mas deve ser executada de forma correta. Primeiro, é necessário acreditar na capacidade dos alunos que possuem um grande potencial de aprendizagem e conhecimento adquirido nos espaços de sociabilidade e o que lhes falta são oportunidades concretas. Cada educado possui potencialidades que devem ser estimuladas pelos educadores e "[...] quem não apostar que existem nas crianças e nos jovens com quem trabalhamos qualidades que, muitas vezes, não se fazem evidentes nos seus atos, não se presta, verdadeiramente, ao trabalho educativo.” (COSTA, 1999, p. 20).

Tendo em vista a realidade escolar, um dos primeiros desafios do educador é comprometer-se com sua formaçáo contínua. O desejo de aprender deve superar o desejo de ensinar. O educador deve compreender que seu aprendizado é contínuo e se dá nos grandes centros de ensino e pesquisa, no encontro ocasional com uma criança que brinca, no simples ato de observar o correr do rio. Devemos considerar que um aprendizado é superior ao outro, que quando há aprendizado somos modificados, e mudar é um princípio básico da prática educativa.

A atitude do mudar está diretamente relacionada com o olhar reflexivo do educador/pesquisador. O seu compromisso com a prática de uma educaçáo humanizada se torna praxis. O olhar atento do educador renova-o e renova sua prática.

Freire (1999) nos convida a rever nossa prática como educadores, mas para isso precisamos nos encontrar dentro do emaranhado mundo da educação, onde as práticas educativas se desenvolvem em um campo político-administrativo que minimiza o valor da escola. Nos reconhecer como educadores possibilita identificar o ponto de partida para saber de que forma podemos educar, ser educados e que transformaçóes podemos realizar na vida e no cotidiano das pessoas com quem trabalhamos. No entanto, transformar significa também reconhecer e respeitar saberes, diversidades, subjetividades e escolhas; pois ensinar exige, sobretudo, respeito aos saberes dos educandos: 
Por isso mesmo pensar certo coloca ao professor ou, mais amplamente, à escola, o dever de não só respeitar os saberes com que os educandos, sobretudo os das classes populares, chegam a ela - saberes socialmente construídos na prática comunitária. (FREIRE, 1999, p. 33).

Nesse pensamento, surge o desejo da ação social, o desejo que extrapola as paredes da escola e visualiza o educando não apenas como receptor de conteúdos, mas como produtor de conhecimentos e transformador de sua própria realidade e a daqueles que o cercam. Podemos visualizar a escola como um espaço educativo e náo como o espaço educativo. Tal pensamento nos convida a repensar a prática pedagógica e o próprio fazer da pedagogia. Para Graciani (2014, p. 31), “[...] fazer pedagogia hoje é também levar em conta esse radicalismo téorico-prático e confrontar-se com o 'pensamento da diferença', assim como o da 'emancipaçáo libertária'.

Podemos entender que a educaçáo acontece em todos os espaços de sociabilidade, seja a casa, seja a rua, seja a escola. Nesse pensamento, reside a Pedagogia Social como fomentadora de espaços educativos e incentivadora da Educação Social. A Pedagogia Social se apresenta no novo contexto histórico como um desafio para os educadores que sonham com mudanças significativas para seus educandos. Para Graciani (2014, p. 20), a Pedagogia Social caracterizase "[...] como uma ciência transversal aberta às necessidades populares que busca enraizar-se na cultura dos povos para, dialeticamente, construir outras possibilidades sem aniquilar o passado, mas promovendo a sua superação.”

$\mathrm{Na}$ Pedagogia Social, o educando deve ser compreendido como um ser possuidor de saberes, e esses saberes são impulsionadores do conhecimento escolar. No entanto, precisam ser cultivados, valorizados e transformados em ações educativas promovidas pelo professor/educador.

\section{De professor a educador}

O professor, como educador social, deve reconhecer-se no cotidiano e reconhecer seu espaço e tempo histórico. Compreender as mudanças políticas, econômicas e sociais que interferem direta ou indiretamente em seu contexto social. Deve visualizar o ser humano como capaz de transformar sua própria vida, como ser capaz de se libertar das amarras viciosas da exclusáo social. Deve ver nas pessoas em situação de vulnerabilidade social saberes que muitas vezes são invisíveis aos olhos e que só podem ser visualizados e sentidos na prática diária. Para Paulo Freire, esse caminho de transformação tem como uma de suas bases o respeito ao outro, ou seja: 
Saber que devo respeito à autonomia, à dignidade e à identidade do educando e, a prática, procurar a coerência com este saber, me leva inapelavelmente à criação de algumas virtudes ou qualidades sem as quais aquele saber vira inautêntico, palavreado vazio e inoperante. De nada serve, a não ser para irritar o educando e desmoralizar o discurso hipócrita do educador, falar em democracia e liberdade mais impor ao educando a vontade de arrogante do mestre. (FREIRE, 1999, p. 69).

Educar não é assumir a postura de ditador, mas sim assumir a postura de aprendiz, de facilitador do diálogo, de potencializador dos saberes e das reflexôes sobre os valores necessários para a vida social cotidiana e globalizada. Seria, talvez, esse o caminho para construção da táo sonhada cidadania, da possibilidade de viver na cidade, não como prisioneiro, dependente da boa ação dos governantes, mas como ativo participante da vida política, como cidadão capaz de mudar seus espaços de sociabilidade.

Para tornar o cidadáo apto a compreender a dinâmica da sociedade e a desenvolver mecanismos de participação, com consciência crítica e autônoma, é preciso romper com a visão ingênua que se tem das forças políticas e dos interesses econômicos que sustentam o status quo que se quer transformar. E é necessário romper com a visão idealista do próprio trabalho educativo, o que significa que o saber pedagógico deve questionar seus pressupostos, seus hábitos e tradições. (GRACIANI, 2014, p.31)

No entanto, o que fizemos até agora foi refletir teoricamente sobre o como deve ser educador. A prática do educador ou educador social ainda caminha entre a utopia e a realidade, sendo ainda difícil encontrar educadores prontos a encarar o desafio da educação social. Viver a educação social significa repensar valores e códigos morais, confrontar sua própria cultura e compreender a realidade cultural da coletividade. Precisa sentir-se agente social capaz de lutar contra as desigualdades e promover a justiça social.

É preciso mergulhar em uma práxis educativa que envolve reflexão-açãoreflexão. A práxis exige do educador social um posicionamento radicalmente democrático, "[...] para tanto, exige uma enorme seriedade no estudo e na formação permanente, a partir da reflexão da prática que o motiva." (GRACIANI, 2014, p.36). Esse seria o caminho para formação do educador social como ser político e emancipado. Para Souza Neto:

O processo de formação e o campo de atuação do educador social são caracterizados por embates ideológicos, açôes de grupos organizados, contendas políticas e religiosas, experiências de injustiça, perdas e frustraçôes. Tal contexto 
sociopolítico exige dele capacidade de se apropriar da realidade e nela intervir pedagogicamente, de mediar relaçōes entre indivíduos, famílias e instituiçōes, de modo a abrir perspectivas para o bem-estar individual e social. (SOUZA NETO, 2010, p. 30).

Cabe considerar que o educador social não pode ser visto como provocador de conflitos, como alguém que incita a violência ou a revolta popular. Deve ser visto como um articulador de saberes, valorizador de culturas e provocador de diálogos. Deve ser capaz de articular os diversos agentes sociais e gerar um ampla rede de garantia de direitos e potencializadora de saberes e competências.

Olhar os alunos em sala de aula, principalmente das escolas públicas, significa desnudá-los do rótulo de aluno e visualizá-los como crianças e adolescentes que muitas vezes são violentados, de várias maneiras, em suas casas, comunidades, pelo Estado e até mesmo pela escola. Assim, desconstruímos nossa rotina de professores e passamos a seguir uma nova rotina de educadores e nossos alunos passam a ser educandos. Para Graciani (2014), o educador deve possuir uma visão crítica e consciente sobre a vida social e sobre os fenômenos causadores da exclusão e da violência. Assim compreendo que o conteúdo escolar, principalmente o disposto nos Livros Didáticos, deve ser complementar ao saber do educando e às suas necessidades cotidianas básicas de aprendizado.

O educador também deve despir-se de preconceitos e visualizar as crianças e adolescentes como pessoas possuidoras de direitos, deveres e principalmente saberes. Nesse caminho, destaca-se a Pedagogia da Convivência (GRACIANI, 2011), ao reconhecer a legitimidade dos direitos da criança e do adolescente: o direito à liberdade, à dignidade, à integridade física, psicológica e moral; bem como à educação gratuita e de qualidade, à saúde, à cultura, ao lazer, à habitaçáo e outros direitos sociais, individuais e coletivos.

A convivência entre educador, crianças e/ou adolescentes promove um encontro de saberes capaz de produzir mudanças significativas em todos. Assim, "num contexto de diferentes saberes e culturas, a educação social abre ao sujeito perspectivas para encontrar o sentido da vida, essencial à realização do ser humano." (SOUZA NETO, 2010, p. 33).

Finalizo esse texto com reflexóes pontuais e reticentes, apresentadas por Costa (1999), que nos questiona sobre que tipo de ser humano pretendemos formar/ educar em nosso país. Esse ser humano deve ser apenas sujeito, ou também agente de sua história? E o que é preciso fazer para que a sociedade brasileira tenha vontade política, a vontade que leva à ação e promova uma educação gratuita e de qualidade? 


\section{Referência}

ARROYO, M. G. (Org.). Da escola carente à escola possível. São Paulo: Loyola, 1991. $183 \mathrm{p}$.

COSTA, A. C. G. Aventura Pedagógica: Caminhos e Descaminhos de uma Ação educativa. Belo Horizonte: Modus Faciendi, 1999. 123 p.

FREIRE, P. Educaçáo Como prática da liberdade. 4a . ed. Rio de Janeiro: Paz e Terra, 1974. 150 p. (Série Ecumenismo e Humanismo).

FREIRE, P. Pedagogia da Autonomia. 12a ed. São Paulo: Ed. Paz e Terra, 1999. 167 p.

GRACIANI, M. S. S. A formaçáo do educador social e a Pedagogia da Convivência. Fundação Banco do Brasil, Brasília. 2011. Disponível em: $<$ http://tecnologiasocial.fbb.org.br/reporter-social/artigos/artigo-a-formacao-doeducador-social-e-a-pedagogia-da-convivencia.htm>. Acesso em: 12 fev. 2014.

GRACIANI, M. S. S. Pedagogia Social. São Paulo: Cortez, 2014. 205 p.

MILET, M. E. (Sup.). Brincadeira com assunto dentro. Salvador: MIAC, 1999. 27 p. OLIVEIRA, F. de. O que é formaçáo para cidadania?- Entrevista com Chico de Oliveira, por Silvio Caccia Bava. Instituto Pólis, São Paulo. 1999. Disponível em: <http://polis.org.br/publicacoes/o-que-e-formacao-para-cidadania/>. Acesso em: 01 mar. 2007.

SOUZA NETO, J. C. de. Pedagogia Social: a formação do educador social e seu campo de atuação. Cadernos de Pesquisas em Educação, Vitória, v. 16, n. 32, p. 29-64. 2010.

TELLES, V. S. Direitos sociais: afinal do que se trata? 2. reimpr. Belo Horizonte: Editora UFMG, 2006. 196 p. 